\title{
Determination of the immunogenic region in the LipL32 protein of Leptospira
}

\author{
Mohammad Iskandar Jumat ${ }^{\mathrm{a}}$, Kenneth Francis Rodrigues ${ }^{\mathrm{a}}$, Azlyna Laribe ${ }^{\mathrm{b}}$, Rashidah \\ Mohammad $^{\mathrm{b}}$, Timothy William ${ }^{\mathrm{c}}$, Daisy Vanitha John ${ }^{\mathrm{a},}$ \\ ${ }^{a}$ Biotechnology Research Institute, Universiti Malaysia Sabah, Kota Kinabalu, Sabah, Malaysia \\ ${ }^{b}$ Public Health Laboratory, Kota Kinabalu, Sabah, Malaysia \\ 'Jesselton Medical Centre, Kota Kinabalu, Sabah, Malaysia
}

Accepted 29th November 2018

\begin{abstract}
Leptospirosis is a zoonotic disease caused by the pathogenic species of Leptospira. The initial symptoms include fever, myalgia, nausea, skin rash, chills, and headache, which can be misdiagnosed. LipL32 is the highly conserved and abundant outer membrane protein (OMP) of Leptospira, which is used as an antigen in serodiagnostic assays. We used three in silico methods to predict the immunodominant regions in the full-length LipL32 protein. We identified three regions, namely the $\mathrm{N}$-terminus (NrLipL32, amino acid sequence $20^{\text {th }}-120^{\text {th }}$ ), intermediate (amino acid sequence $120^{\text {th }}-150^{\text {th }}$ ), and C-terminus (CrLipL32, amino acid sequence $160^{\text {th }}-260^{\text {th }}$ ) regions. The full-length protein and two larger fragments were cloned into the pET22b plasmid and expressed in Escherichia coli BL21 (DE3). The purified proteins were used as antigens in an ELISA to detect Leptospira-specific antibodies. The CrLipL32 ELISA showed the highest sensitivity for IgM $(73.3 \%)$ and IgG (65\%), followed by the full-length rLipL32 ELISA (IgM $68 \%$ and IgG 60\%). The full-length rLipL32 ELISA showed high specificity (IgM 85\% and IgG 75\%), followed by the NrLipL32 ELISA (IgM 75\% and IgG 60\%). The intermediate fragment showed very low sensitivity (IgM 17\% and IgG 2\%). The sensitivity of the rLipL32 ELISA could be enhanced by adding other OMPs of Leptospira.
\end{abstract}

Keywords: ELISA, immunodominant region, in silico prediction, Leptospira, LipL32 protein

\section{INTRODUCTION}

Leptospirosis is a zoonotic disease of global importance. It is caused by the pathogenic species of Leptospira (Levett, 2001). The initial symptoms of leptospirosis include fever, myalgia, nausea, skin rash, chills, and headache, which can be misdiagnosed for other acute febrile diseases, such as dengue fever, malaria, melioidosis, and others (Dutta and Christopher, 2005). Currently, the gold standard for diagnosing leptospirosis is the microscopic agglutination test (MAT), which causes the agglutination of antibodies in suspected serum samples when mixed with a panel of live strains of Leptospira obtained from locally isolated serovars. However, the MAT assay is quite laborious and hazardous, since live pathogenic strains of Leptospira need to be maintained in the laboratory (Pappas et al., 1985). Serological tests, for example, ELISA, have been used to detect the presence of Leptospira-specific antibodies that are produced after five to seven days of infection (Chapman et al., 1991). The outer membrane proteins (OMPs) of Leptospira, such as LipL32, LipL41, and LigA, have been used as antigens in serodiagnostic assays (Shang et al.,

\footnotetext{
* Author for correspondence: Daisy Vanitha John, Biotechnology Research Institute, University Malaysia Sabah, Kota Kinabalu, Sabah, Malaysia. Email - daisyvanitha@gmail.com
} 
1996; Flannery et al., 2001; Palaniappan et al., 2002). Among these OMPs, LipL32 has been reported to be the most suitable antigen for diagnosing leptospirosis, since it is highly conserved and found abundantly in the pathogenic Leptospira OMP profile (Haake et al., 2000). A truncated LipL32 (tLipL32) that was designed for stability, which contains the major epitopes expressed in Escherichia coli and Pichia pastoris, was able to differentiate experimentally infected laboratory rat sera and field rat sera, respectively, from control rat sera in ELISA, indicating that tLipL32 is applicable as a serodiagnostic antigen (Shiokawa et al., 2016). Three amino-terminal peptides of the BBK07 protein of Borrelia burgdorferi were shown to be superior when compared to the full-length BBK07 protein in terms of the serodiagnosis of Lyme disease by ELISA, since it was possible to detect specific antibodies generated during the early stages of the disease (Coleman et al., 2011). Previously, the antigenic regions in the OMPs of Leptospira, for example, LigA and LipL21, were determined using either a bioinformatic analysis or randomly selected peptides obtained from libraries (Tungtrakanpoung et al., 2006; Wiwanitkit, 2007; Lin et al., 2008). Furthermore, Lottersberger et al. (2009) determined the antigenic regions of LipL32 using peptide arrays.

Bioinformatic algorithms have been used to predict the number of possible epitopes within an immunogenic region of an antigen in order to lessen the required experimental efforts. Hopp and Woods' (1981) hydrophilicity scale hypothesizes that the antigenic determinants are located on the hydrophilic site, while the nonantigenic determinants are shielded and located on the hydrophobic region. Several other algorithms can be used to predict epitopes based on different chemical and physical properties of amino acids, including solvent accessibility, secondary structure, antigenicity, flexibility, etc. (Garnier et al., 1978; Kyte and Doolittle, 1982; Eisenberg et al., 1984; Karplus and Schulz, 1985; Welling et al., 1985; Jameson and Wolf, 1988; Pellequer et al., 1993). In this study, the immunogenic regions of LipL32 were predicted using three in silico algorithms. The fragments were cloned and produced in E. coli. The purified proteins were tested in ELISA using MATpositive and MAT-negative serum samples to determine the immunodominant region that is most suitable for serodiagnostic assays.

\section{MATERIALS AND METHODS}

Clinical samples and preparation of the rLipl32 protein. The human serum samples $(60$ MAT-positive and 40 MAT-negative tested against $L$. interrogans) used in this study were provided by the Kota Kinabalu Public Health Laboratory, Sabah, Malaysia. All the serum samples were stored at $-20^{\circ} \mathrm{C}$ until they were tested. The study was approved by the Medical Research and Ethical Committee, Ministry of Health Malaysia (study number NMRR-13-67715713). A detailed protocol for the production of synthetic recombinant LipL32 protein was previously described (Yaacob et al., 2017).

\section{Determination of the LipL32 antigenic regions using in silico methods and preparation of the LipL32 fragments. The} amino acid sequence of the full-length LipL32 (accession number ACZ73827.1) retrieved from the National Center for Biotechnology Information (NCBI) database was analyzed for possible antigenic regions using bioinformatic algorithms available in ProtScale (Gasteiger et al., 2005). The three bioinformatic algorithms used were Kyte and Doolittle's hydrophobicity scale, the propensity, and the recognition factor (Kyte and Doolittle, 1982; Kolaskar and Tongaonkar, 1990; Fraga, 1982). The overlapping regions that correspond to the predictions were divided into three fragments, namely the $\mathrm{N}$-terminus (NrLipL32, amino acid sequence $20^{\text {th }}-120^{\text {th }}$ ), intermediate (amino acid sequence $120^{\text {th }}-150^{\text {th }}$ ), and C-terminus (CrLipL32, amino acid sequence $\left.160^{\text {th }}-260^{\text {th }}\right)$ regions. The $\mathrm{N}$ - and C-terminal region sequences were sub-cloned into expression vectors by Shanghai ShineGene Molecular Biotech Inc. The proteins were expressed in E. coli and then purified using affinity chromatography by Kinabalu Adventure Supply, Sabah, Malaysia. The full-length rLipL32 and the two protein fragments were analyzed using 15\% SDS-PAGE, and the bands were sent for LC/MS/MS analysis (First BASE Laboratories Sdn Bhd). The intermediate fragment (ATPEEKSMPHWFDT 
WIRVERMSAIMPDQIAKAAKAKPVQK) was synthesized as a peptide by First BASE Laboratories Sdn. Bhd., Kuala Lumpur, Malaysia, with a purity of $70 \%$. The peptide was then resuspended in phosphate-buffered saline (PBS) and stored at $-20^{\circ} \mathrm{C}$ for further use.

\section{Determination of the immunodominant} region in LipL32 by ELISA. Optimized amount of purified $\mathrm{rLipL} 32 \quad(0.25 \mu \mathrm{g} / 50 \quad \mu \mathrm{l}$ well), NrLipL32 (0.5 $\mu \mathrm{g} / 50 \mu \mathrm{l}$ well), CrLipL32 (0.5 $\mu \mathrm{g} / 50 \mu \mathrm{l}$ well), and the intermediate LipL32 fragment $(0.125 \mu \mathrm{g} / 50 \mu \mathrm{l}$ well $)$ were used to coat 96-well MaxiSorp immunoassay plates (Nunc, Denmark), and the ELISA was performed as previously described (Yaacob et al., 2017). In order to determine the concentrations of antibodies in the serum samples, a standard curve was obtained using human IgM and IgG (25$0.0488 \mathrm{ng} / \mathrm{ml})$. Positive and negative controls were included in each assay. A serum sample was considered to be positive when the concentration of Leptospira-specific antibody was two-fold higher than that of the negative control. The sensitivity and specificity of the ELISA for the detection of Leptospira-specific IgM and IgG were calculated using the MAT as the gold standard. The performance of the rLipL32-based ELISA was assessed by participation in an external quality control program, namely the Royal College of Pathologists of Australasia Quality Assurance Programs (RCPAQAP). Four samples were received and tested at two separate time points in ELISA.

\section{RESULTS}

\section{Recombinant LipL32 (rLipL32) ELISA is able to detect Leptospira-specific antibodies.} The SDS-PAGE analysis of the full-length rLipL32 expressed in E.coli showed that it had a molecular mass of approximately $35 \mathrm{kDa}$. The LC/MS/MS result revealed that rLipL32 expressed is from the OMP of the pathogenic Leptospira (Supplementary Data). The comparison of the MAT and the full-length rLipL32 ELISA is shown in Figure 1. Of the 60 MAT-positive serum samples, $41(68 \%)$ samples tested positive for Leptospira-specific IgM $(>1.0 \mathrm{ng} / \mathrm{ml})$, while 19 samples $(32 \%)$ tested negative $(<0.9 \mathrm{ng} / \mathrm{ml})$ according to the ELISA. Thirty-six samples $(60 \%)$ tested positive for Leptospira-specific IgG $(>1.0$ $\mathrm{ng} / \mathrm{ml}$ ) and 24 samples $(40 \%)$ tested negative $(<0.9 \mathrm{ng} / \mathrm{ml})$. Among the $40 \mathrm{MAT}$-negative samples, Leptospira-specific IgM was absent from 34 samples $(85 \%,<0.9 \mathrm{ng} / \mathrm{mL})$, while six samples $(15 \%)$ tested positive, with the amount of IgM antibodies in those samples ranging from 2.7 to $5.9 \mathrm{ng} / \mathrm{ml}$. Thirty samples $(75 \%)$ also tested negative for Leptospira-specific IgG $(<1.0 \mathrm{ng} / \mathrm{ml})$, while ten samples $(25 \%)$ tested positive according to the ELISA, with the amount of IgG antibodies in those samples ranging from 1.7 to $6.4 \mathrm{ng} / \mathrm{ml}$. The ELISA using the rLipL32 antigen was able to correctly detect the presence of Leptospira-specific IgM and IgG in two samples, as well as their absence from the two samples obtained from the RCPAQAP, with a score of $100 \%$.

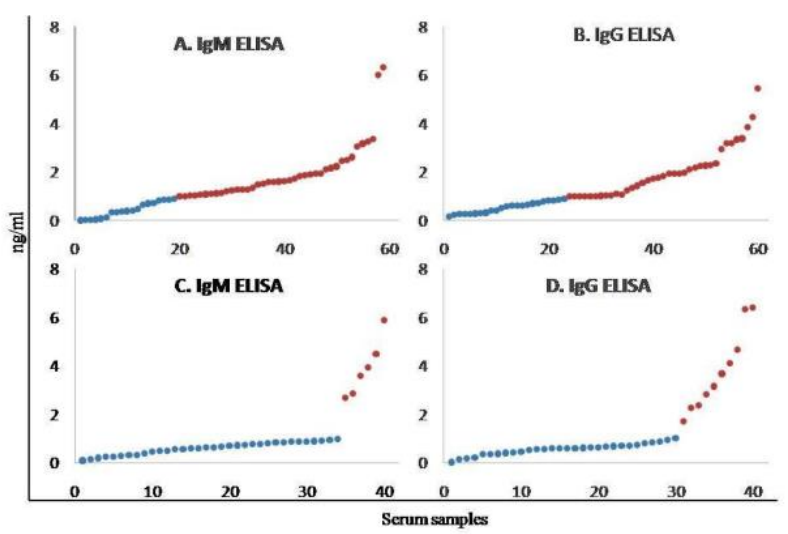

Figure 1. Levels of Leptospira-specific antibodies in the MAT-positive (A and B) and MAT-negative ( $C$ and $\mathrm{D}$ ) human serum samples obtained using the rLipL32-based ELISA. The blue dot represents the negative serum sample according to the ELISA, while the red dot represents the positive sample.

Three antigenic regions in Leptospira LipL32 were predicted using in silico methods. The possible antigenic regions in full-length LipL32 were predicted using Kyte and Doolittle's hydrophobicity scale, the recognition factor, and the propensity (Fraga, 1982; Kyte and Doolittle, 1982; Kolaskar and Tongaonkar, 1990). The overlapping regions that correspond to the bioinformatic predictions were divided into three fragments, which were identified as NrLipL32 (amino acid sequence $20^{\text {th }}-120^{\text {th }}$ ), the intermediate fragment (amino acid sequence $120^{\text {th }}-150^{\text {th }}$ ), and 
CrLipL32 (amino acid 160 ${ }^{\text {th }}-260^{\text {th }}$ ). The recombinant NrLipL32 and CrLipL32 proteins expressed in E. coli showed a molecular mass of $15 \mathrm{kDa}$ in the SDS-PAGE analysis. SDS-PAGE profile of the CrLipL32 is shown in Figure 2. In the LC/MS/MS analysis, the sequences of these two fragments exhibited a high score, which confirmed that they are part of the Leptospira LipL32 OMP (Supplementary Data).

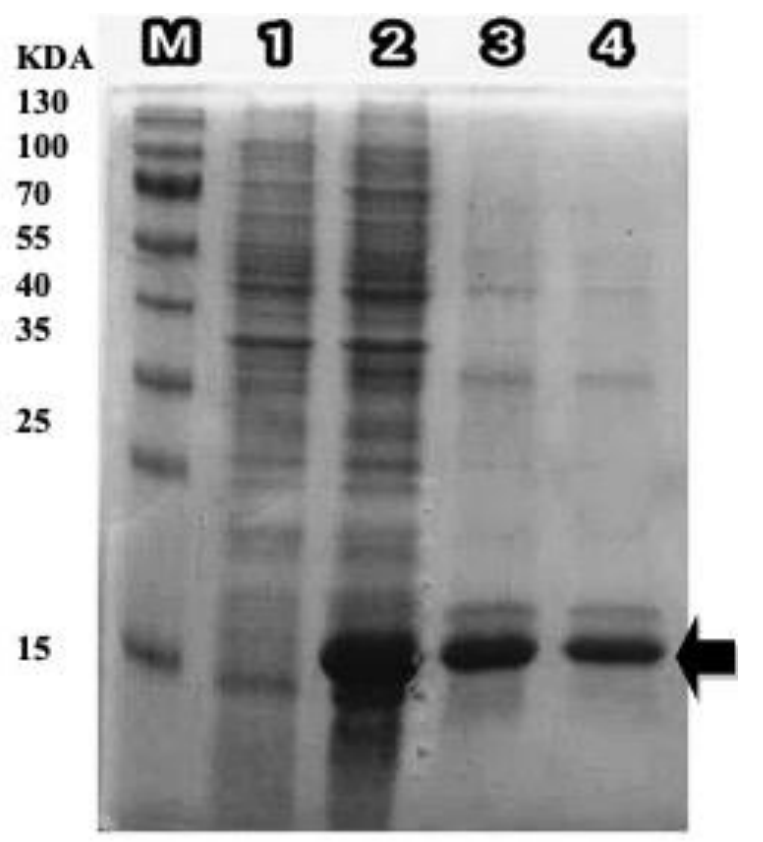

Figure 2. SDS-PAGE of the CrLipL32. M: molecular weight marker; Lane 1: total protein of the uninduced cells; Lane 2: total protein of the induced cells; Lane 3: purified and refolded CrLipL32; Lane 4: modified His-tag-purified CrLipL32. Arrow indicates CrLipL32 protein.

\section{The $C$-terminal region is more immunogenic than the $\mathbf{N}$-terminal and intermediate regions of LipL32. Table 1 shows the presence of Leptospira-specific antibodies in the human serum samples, as determined by ELISA using the full- length rLipL32 protein and its three fragments as antigens in MAT-positive and MAT-negative serum samples, as well as their sensitivity and specificity. Of the 60 MAT-positive samples, CrLipL32 detected the highest number of samples that tested positive for both IgM (44 samples, $73 \%$ ) and $\operatorname{IgG}$ (39 samples, 65\%), followed by the full-length rLipL32 (IgM: 41 samples, 68\%; IgG: 36 samples, 60\%) and NrLipL32 (IgM: 31 samples, 52\%; IgG: 28 samples, 47\%). Only very few samples tested positive when the intermediate}

fragment was used (IgM: ten samples, 16\%; IgG: one sample, $2 \%$ ). Among the 40 MAT-negative serum samples, the full-length rLipL32 showed the highest number of samples that tested negative for IgM (34 samples, 85\%) and IgG (30 samples, $75 \%$ ), followed by the NrLipL32 (IgM: 30 samples, 75\%; IgG: 24 samples, 60\%) and CrLipL32 (IgM: 23 samples, 58\%; IgG: 20 samples, 50\%). Although the intermediate fragment showed a high number of negative results for both IgM (33 samples) and $\operatorname{IgG}$ (40 samples), such a finding could not be considered valid because the fragment showed very low sensitivity in relation to the MAT-positive serum samples. The ELISA using the NrLipL32 gave a score of $100 \%$ for RCPAQAP program samples while the CrLipL32 failed to detect one positive sample.

\section{DISCUSSION}

The identification of new immunodominant antigens of LipL32 could serve to improve the current laboratory diagnosis of leptospirosis. In this study, the possible antigenic regions of LipL32 were identified using in silico prediction methods and then tested with an ELISA to determine the most immunodominant fragment of LipL32 for serodiagnostic assays. Kyte and Doolittle's (1982) hydrophilicity scale predicts that the antigenic regions are located at the hydrophilic site of a protein with negative values, while hydrophobic sites contain non-antigenic regions with positive values. The recognition factor predicts the antigenic regions based on the energy binding of an amino acid. Amino acids with low binding energy will interact less with other amino acids and thus binding is specific. Regions that contain these amino acid sequences are likely to be possible antigenic regions (Fraga, 1982). The propensity scale determines the antigenic regions based on the occurrence of an amino acid within a given number of epitopes. The higher the number of occurrences, the higher the likelihood of an amino acid being associated with the antigenic region, and there were eight such antigenic regions in LipL32 (Kolaskar and Tongaonkar, 1990). 
Table 1. Comparison of the full-length rLipL32 and its fragments in ELISA.

\begin{tabular}{|c|c|c|c|c|c|c|}
\hline Protein & & & $\begin{array}{r}\text { MAT + } \\
(\mathrm{n}=60)\end{array}$ & Sensitivity & $\begin{array}{c}\text { Mat - } \\
(\mathrm{n}=40)\end{array}$ & Specificity \\
\hline \multirow{4}{*}{ rLipL32 } & \multirow{2}{*}{$\operatorname{IgM}$} & + & 41 & \multirow{2}{*}{$68 \%$} & 6 & \multirow{2}{*}{$85 \%$} \\
\hline & & - & 19 & & 34 & \\
\hline & \multirow{2}{*}{$\operatorname{IgG}$} & + & 36 & \multirow{2}{*}{$60 \%$} & 10 & \multirow{2}{*}{$75 \%$} \\
\hline & & - & 24 & & 30 & \\
\hline \multirow{4}{*}{ NrLipL32 } & \multirow{2}{*}{ IgM } & + & 31 & \multirow{2}{*}{$52 \%$} & 10 & \multirow{2}{*}{$75 \%$} \\
\hline & & - & 29 & & 30 & \\
\hline & \multirow{2}{*}{$\operatorname{IgG}$} & + & 28 & \multirow{2}{*}{$47 \%$} & 16 & \multirow{2}{*}{$60 \%$} \\
\hline & & - & 32 & & 24 & \\
\hline \multirow{4}{*}{ Intermediate } & \multirow{2}{*}{$\operatorname{IgM}$} & + & 10 & \multirow{2}{*}{$17 \%$} & 7 & \multirow{2}{*}{ - } \\
\hline & & - & 50 & & 33 & \\
\hline & \multirow{2}{*}{$\operatorname{Ig} G$} & + & 1 & \multirow{2}{*}{$2 \%$} & 0 & \multirow[b]{2}{*}{ - } \\
\hline & & - & 59 & & 40 & \\
\hline \multirow{4}{*}{ CrLipL32 } & \multirow{2}{*}{$\operatorname{IgM}$} & + & 44 & \multirow{2}{*}{$74 \%$} & 17 & \multirow{2}{*}{$58 \%$} \\
\hline & & - & 16 & & 23 & \\
\hline & \multirow{2}{*}{$\mathrm{IgG}$} & + & 39 & \multirow{2}{*}{$65 \%$} & 20 & \multirow{2}{*}{$50 \%$} \\
\hline & & - & 21 & & 20 & \\
\hline
\end{tabular}

+ = Positive; - = Negative; $\mathrm{n}=$ number of samples

When compared to the full-length rLipL32, the Cterminal region detected more positive samples among the MAT-positive samples, which shows that this region may feature more immunogenic epitopes. It has been reported that the CrLipL32 consists of two immune-reactive regions, namely the amino acid sequences $151^{\text {st }}-177^{\text {th }}$ and $181^{\text {st }}$ $204^{\text {th }}$ (Lottersberger et al., 2009). Huak et al. (2008) identified the C-terminal domain (amino acid sequence $185^{\text {th }}-272^{\text {th }}$ ) of the LipL32 as the primary immunological target, and the IgM response against this subfragment was detected in both acute- and convalescent-phase serum samples. Since reactivity against the $\mathrm{C}$-terminus region can be detected earlier in the course of infection, this region can be utilized in serodiagnostic assays for the early detection of leptospirosis (Hauk et al., 2008; Lottersberger et al., 2009). The positive IgM and IgG ELISA results obtained for the MATnegative samples using the CrLipL32 indicate that this antigen is able to detect sub-surface nonagglutinating antibodies that could otherwise have been missed by the MAT (Chapman et al., 1991). However, the cross-reactivity of this antigen needs to be confirmed using serum samples obtained from healthy controls from a nonendemic region or by performing polymerase chain reaction (PCR) during the first few days of infection whenever possible. The NrLipL32 ELISA showed only moderate sensitivity for both
$\operatorname{IgM}$ and $\operatorname{IgG}$, while no reactivity on the part of this region (amino acid sequence $21^{\text {st }}-92^{\text {nd }}$ ) was reported by Hauk et al. (2008). The intermediate fragment showed the lowest sensitivity for IgM and $\operatorname{IgG}$ among all the fragments; hence, this region may not be immunogenic. Although the full-length rLipL32 showed low sensitivity when compared to the CrLipL32, it showed less nonspecific binding in the MAT- negative samples, which suggests that this antigen is ideal for serodiagnosis at the present moment. Previous studies have reported higher sensitivity (90-95\%) and specificity (83-90\%) for this antigen in ELISA (Sun et al., 2011; Chen et al., 2013; Vedhagiri et al., 2013; Alizadeh et al., 2014; Chandy et al., 2017). In addition, the intact LipL32 showed higher sensitivity in detecting IgG response compared to C-terminus ( $100 \%$ vs $42 \%)$ both in the acute and convalescent serum samples of laboratory confirmed cases of leptospirosis (Hauk et al., 2008). A discrepancy between the MAT and ELISA results was observed in this study. Only relatively little correlation between the MAT and enzyme immunoassays (EIA) was previously reported, particularly when the serum samples were obtained a few days after the onset of symptoms. During this period, there was no corresponding MAT titer against the infecting serovar, while the serum samples tested positive for IgM and IgG in the enzyme assays (Chapman 
et al., 1991). Since the MAT assay does not distinguish between $\operatorname{IgM}$ and $\operatorname{IgG}$, it may not be an ideal method of comparison, particularly with regard to the IgM response. The recombinant rLipL32 ELISA was able to correctly identify the negative samples obtained from the RCPAQAP program, which shows that the assay is specific for the detection of Leptospira-specific antibodies. The assay was also able to correctly identify positive samples with a greater degree of accuracy, which demonstrates that the assay is sensitive in detecting Leptospira-specific antibodies in serum samples.

\section{CONCLUSION}

Of the three fragments of rLipL32 tested, the CrLipL32 had the highest sensitivity for both IgM and IgG in terms of detecting Leptospira-specific antibodies, which shows that it is the most immunogenic region in the LipL32 protein. It can hence be utilized in serodiagnostic assays for the early detection of leptospirosis. The full-length rLipL32 ELISA showed moderate sensitivity and high specificity for the detection of both IgM and IgG. The addition of other OMPs, for example, LipL41 and LigA, to this recombinant antigen might improve the sensitivity of the ELISA assay (Wiwanitkit et al., 2007; Lin et al., 2008).

\section{ACKNOWLEDGEMENTS}

This study was supported by grants from the Ministry of Higher Education, Malaysia (FRG0407-SG-1/2015) and the UMS Innovation Grant (SGI0023).

\section{REFERENCES}

Alizadeh, S. A., Abdolahpour, G., Pourmand, M. R., Naserpour, T., Najafipour, R. \& Eshraghi, S. S. 2014. Evaluation of New ELISA based on rLsa63-rLipL32 antigens for serodiagnosis of human leptospirosis. Iranian Journal of Microbiology 6(3): 184-189.

Chandy, S., Kirubanandhan, L., Hemavathy, P., Khadeeja, A. M., Kurian, S. J., Venkataraman, K., Mørch, K., Mathai, D. \& Manoharan, A. 2017. Serovar prevalence of Leptospira in semirural India and the development of an IgM-based indirect ELISA. Journal of Infection in Developing Countries 11(3): 234-241.

Chapman, A. J., Everard, C. O., Faine, S. \& Adler, B. 1991. Antigens recognized by the human immune response to severe leptospirosis in Barbados. Epidemiology and Infection 107(1): 143-155.

Chen, H. W., Zhang, Z., Halsey, E. S., Guevara, C., Canal, E., Hall, E., Maves, R., Tilley D. H., Kochel T. J. \& Ching, W. M. 2013. Detection of Leptospira-specific antibodies using a recombinant antigen-based enzyme-linked immunosorbent assay. American Journal of Tropical Medicine and Hygiene 89(6): 1088-1094.

Coleman, A. S., Rossmann, E., Yang, X., Song, H., Lamichhane, C. M., Iyer, R., Schwartz, I. \& Pal, U. 2011. BBK07 immunodominant peptides as serodiagnostic markers of Lyme disease. Clinical and Vaccine Immunology 18(3): 406413.

Dutta, T. K. \& Christopher, M. 2005. Leptospirosis-An Overview. Journal of the Association of Physicians of India 53: 545-551.

Eisenberg, D., Weiss, R. M. \& Terwilliger, T. C. 1984. The hydrophobic moment detects periodicity in protein hydrophobicity. Proceedings of the National Academy of Sciences 81(1): 140-144.

Flannery, B., Costa, D., Carvalho, F. P., Guerreiro, H., Matsunaga, J., Da Silva, E. D., Ferreira A. G., Riley, W. G., Reis, M. G., Haake, D. A. \& Ko, A. I. 2001. Evaluation of recombinant Leptospira antigen-based enzyme-linked immunosorbent assays for the serodiagnosis of leptospirosis. Journal of Clinical Microbiology 39(9): 33033310.

Fraga, S. 1982. Theoretical prediction of protein antigenic determinants from amino acids sequences. Canadian Journal of Chemistry 60: 2606-2610.

Garnier, J., Osguthorpe, D. J. \& Robson, B. 1978. Analysis of the accuracy and implications of simple methods for predicting the secondary structure of globular proteins. Journal of Molecular Biology 120(1): 97-120.

Gasteiger, E., Hoogland, C., Gattiker, A., Duvaud, S., Wilkins, M. R., Appel, R. D. \& Bairoch, A. 2005. Protein identification and analysis tools on the ExPASy server. In The Proteomics Protocols Handbook. ed. J. M. Walker, pp. 571-607. Totowa, NJ: Humana Press.

Haake, D. A., Chao, G., Zuerner, R. L., Barnett, J. K., Barnett, D., Mazel, M., Matsunaga, J., Levett, P. N. \& Bolin, C. A. 2000. The leptospiral major outer membrane protein LipL32 is a lipoprotein expressed during mammalian infection. Infection Immunity 68: 2276-2285.

Hauk, P., Macedo, F., Romero, E. C., Vasconcellos, S. A., de Morais, Z. M., Barbosa A. S. \& Ho, P. L. (2008). In LipL32, the major leptospiral lipoprotein, the $\mathrm{C}$ terminus is the primary immunogenic domain and mediates interaction with collagen IV and plasma fibronectin. Infection Immunity 76: 2642-2650.

Hopp, T. P. \& Woods, K. R. 1981. Prediction of protein antigenic determinants from amino acid sequences. Proceedings of the National Academy of Sciences 78: 3824-3828.

Jameson, B. A. \& Wolf, H. 1988. The antigenic index: a novel algorithm for predicting antigenic determinants. Computer Application in the Biosciences 4(1): 181-186.

Karplus, P. A. \& Schulz, G. E. 1985. Prediction of chain flexibility in proteins. A tool for the selection of peptide antigens. Naturwissenschaften 72: 212-213.

Kolaskar, A. S. \& Tongaonkar, P. C. 1990. A semi-empirical method for prediction of antigenic determinants on protein antigens. FEBS Letters 1(2): 172-174. 
Kyte, J. \& Doolittle, R. F. 1982. A simple method for displaying the hydropathic character of a protein. Journal of Molecular Biology 157: 105-132.

Levett, N. 2001. Leptospirosis. Clinical Microbiology Reviens 14(2): 296-326.

Lin, X., Pan, J., Lou, Y., Mao, Y., Li, L. \& Yan, J. 2008. Prediction and identification of antigenic epitopes in genus specific outer membrane protein OmpL1 and LipL21 of Leptospira interrogans. Chinese Journal of Microbiology and Immunology 28: 343-347.

Lottersberge, J., Guerrero, S. A., Tonarelli, G. G., Frank, R., Tarabla, H. \& Vanasco, N.B. 2009. Epitope mapping of pathogenic Leptospira LipL32. Letters in Applied Microbiology 49: 641-645.

Pellequer, J. L., Westhof, E. \& Van Regenmortel, M. H. 1993. Correlation between the location of antigenic sites and the prediction of turns in proteins. Immunology Letters 36(1): 83-99.

Palaniappan, R. U., Chang, Y. F., Jusuf, S. S. Artiushin, S, Timoney, J. F., McDonough, S. P., Barr, S. C., Divers, T. J., Simpson, K. W., McDonough, P. L. \& Mohammed, H. O. 2002. Cloning and Molecular Characterization of an Immunogenic LigA protein of Leptospira interrogans. Infection Immunity 70(11): 5924-5930.

Pappas, M. G., Ballow, R. W., Gray, M. R., Takafuji, E. T., Miller, R. N. \& Hockmeyer, W. T. 1985. Rapid serodiagnosis of leptospirosis using the $\operatorname{IgM}$ specific dot-ELISA: comparison with the microscopic agglutination test. The American Journal of Tropical Medicine and Hygiene 34: 346-354.

Shang, E. S., Summers, T. A. and Haake, D. A. 1996. Molecular cloning and sequence analysis of the gene encoding LipL41, a surface-exposed lipoprotein of pathogenic Leptospira species. Infection Immunity 64: 2322-2330.

Shiokawa, K., Gamage, C. D., Koizumi, N., Sakoda, Y., Shimizu, K., Tsuda, Y., Yoshimatsu, K., Arikawa, J. 2016. Evaluation of truncated LipL32 expressed by Escherichia coli and Pichia pastoris for serodiagnosis of Leptospira infection in rodents. Journal Veterinary Medical Science 78(2): 221-230.

Sun, A., Wang, Y., Du, P., Wu, S. \& Yan, J. 2011. A sensitive and specific IgM ELISA for the serological diagnosis of human leptospirosis using a rLipL32/1-LipL21OMPL1/2 fusion protein. Biomedical and Environmental Sciences 24(3): 291-299.

Tungtrakanpoung R, Pitaksaijakul P, Na-Ngarm N, Chaicumpa W, Ekpo, P., Saengjaruk P., Froman, G. \& Ramasoota, P. 2006. Mimotope of Leptospira from phage-displayed random peptide library is reactive with both monoclonal antibodies and patients' sera. Veterinary Microbiology 115: 54-63.

Vedhagiri, K., Velineni, S., Timoney, J. F., Shanmughapriya, S., Vijayachari, P., Narayanan, R. \& Natarajaseenivasan, K. 2013. Detection of LipL32-specific IgM by ELISA in sera of patients with a clinical diagnosis of leptospirosis. Pathogens of Global Health 107(3): 130-135.

Welling, G. W., Weijer, W. J., van der Zee, R. \& Welling-Wester, S. 1985. Prediction of sequential antigenic regions in proteins. FEBS Letters 188(2): 215-218.

Wiwanitkit, V. 2006. Predicted epitopes of Lig A of Leptospira interrogans by bioinformatics method: a clue for further vaccine development. V accine 25: 2768-2770.

Yaacob, Y., Rodrigues, K. F., Opook, F., William, T. \& John D. V. 2017. Recombinant LipL32 protein developed using a synthetic gene detects Leptospira-specific antibodies in human serum samples. Malaysian Journal Medical Sciences 24(5): 44-51. 